\title{
Effects of Diphenylhydantoin on Transport Processes in Frog Skin (Rana ridibunda)
}

Diphenylhydantoin (DPH) has been used as an antiepileptic and as an antiarrhythmic agent for many years ${ }^{1,2}$. Although it is well established that it affects a wide variety of cells, its mechanism of action is largely unknown. Recent work on muscle and brain tissue ${ }^{3-5}$ has yielded conflicting results as to the effect of DPH on the $\mathrm{Na}+\mathrm{K}$-ATPase, some authors claiming a stimulation ${ }^{4}$, others an inhibition of the enzyme ${ }^{5}$. The consensus, however, is that DPH somehow acts upon ion movements across cell membranes. It thus seemed justified to investigate the effects of DPH on a polar epithelium such as frog skin, a tissue offering a convenient model for the study of sodium transport in vitro, under well defined experimental conditions. A preliminary report of this work has been presented elsewhere ${ }^{6}$.

Materials and methods. The ventral skin of frogs (Rana ridibunda) was mounted in lucite double chambers filled with aerated Ringer solutions of a standard composition ${ }^{7}$. The skin itself was sandwiched between nylon meshes and clamped between lucite plates provided with 2 rectangular windows. It was thus possible to expose 2 independent areas of the same skin to Ringer solutions contained in adjacent chambers, one area of the skin being used as control of the other. It was also possible to conduct 'cross experiments' in which the sequence of hormones or drugs presented to the control skin was reversed with respect to the test skin. Two types of chamber were used: a 'large' chamber with windows of $3.5 \mathrm{~cm}^{2}$ each and $30 \mathrm{ml}$ of Ringer solution on each side of the skin, and a 'small' chamber with windows of $2.0 \mathrm{~cm}^{2}$ and a volume of $5 \mathrm{ml}$.

Electrical parameters, i.e., the electrical potential difference (PD) across the skin and the short circuit current (SCC), were monitored continuously by standard techniques. Measurements of $\mathrm{PD}$ were done by means of calomel half-cells connected to the chambers by $3 M \mathrm{KCl}$ agar bridges. To measure SCC, silver-silver chloride electrodes were positioned at opposite sides of the chamber, facing the membrane. Two types of voltage clamp were used: 1 . with the first type, allowing for correction of the fluid resistance between the tips of the bridges and the skin, PD or SCC were monitored continuously; 2 . with the second type PD and SCC were monitored sequentially in an automatic 2 min cycle. Recording of both parameters was provided by a G-2000 Varian strip-chart recorder.

Results and discussion. The addition of DPH $(33 \mu \mathrm{g} / \mathrm{mI})$ to the medium bathing the external side of the skin resulted in a rapid, sustained rise in PD, as shown in Figure 1. This effect persisted unchanged for hours, in stable membranes $^{8}$. A similar rise, following the same time-course, was observed for SCC (Figure 2), the overall effect being an increase in conductance. Three other typical features of the action of DPH on frog skin can be seen in Figure 2: the reversibility, reproducibility and parallelism of the increase of SCC in 2 independent areas of the same skin. In a total of 66 experiments, increments in SCC ranged from 12 to $166 \%$, with most values between 20 and $50 \%$. The highest responses were observed during the months of October to December, in particular shortly after moulting of the skin ${ }^{9}$. In contrast, addition of the same amount of $\mathrm{DPH}(33 \mu \mathrm{g} / \mathrm{ml})$ to the internal side of the skin was without noticeable effect under these experimental conditions.

The effects of DPH, added to the external side of frog skin, mimic those of oxytocin, added to the internal side of the same epithelium : both substances increase PD and SCC with an overall increase in conductance. Consequent$l_{y}$, it seemed interesting to study the interaction between DPH and oxytocin in this amphibian epithelium. Typical aspects of such interaction are shown in Figure 1. The rise in $\mathrm{PD}$ produced by oxytocin was not modified by prior exposure of the skin to DPH. Conversely, the response to

1 H. H. Merritt and T. J. Putnam, J. Am. med. Ass. 117, 1068 (1938)

2 W. A. Leonard, Archs intern. Med. 101, 714 (1958).

${ }^{3}$ J. B. Peter, Biochim. biophys. Res. Commun 40, 1362 (1970).

4 B. W. FEstoff and S. H. APPEL, J. clin. Invest. 47, $27 \mathbf{5} 2$ (1968). ${ }^{5}$ M. D. Rawson and J. H. Prncus, Biochem. Pharmac. 17, 573 (1968).

${ }^{6}$ R. C. DE Sousa and A. Grosso, Experientia 28, 732 (1972).

${ }^{7}$ F. BASTIDE et S. JARD, Biochim. biophys. Acta 150, 113 (1968).

8 The dose chosen in these studies is in the range of the therapeutic doses and is frequently used in in vitro studies with DPH. In a few experiments, doubling the dose resulted in a very small additional increase in the DPH effect.

${ }^{\circ}$ Such variability is not uncommon in amphibian epithelia and is also observed in response to hormones like oxytocin or vasopressin.

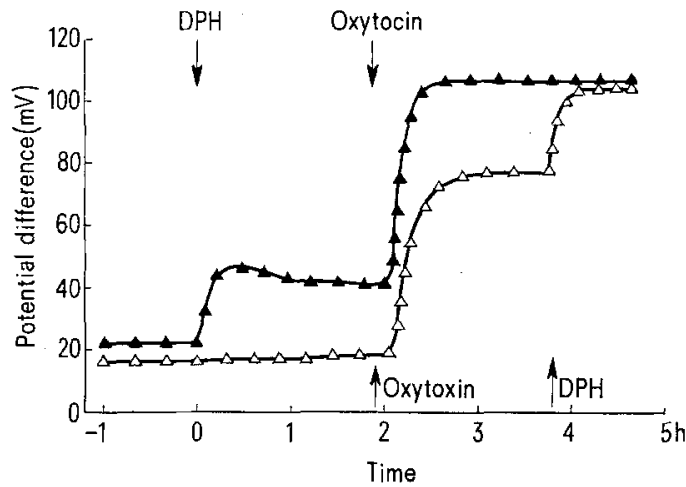

Fig. 1. Changes in PD induced by DPH and oxytocin on 2 adjacent areas of frog skin. DPH was added to the external side and oxytocin to the internal side of the skin. Set up: 'large' double chamber and clamp type 1 (see Methods). In this and the following figures, symbols refer to 2 areas of a single skin.

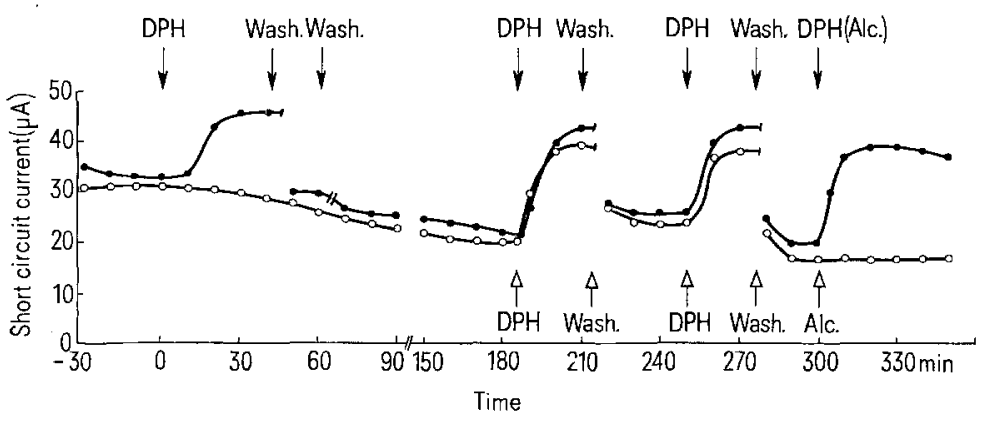

Fig. 2. Iterative stimulation of SCC by DPH on frog skin. Note reversibility, reproducibility and parallelism of the effects of DPH. Set up as in Figure 1.

Wash. $=$ washing. Alc. $=$ alcohol 
DPH was unaffected by previous stimulation with oxytocin, the effects of the 2 substances being additive. The same applies, pari passu, to the effects of DPH and oxytocin on SCC, as confirmed by statistical analysis. The fact that the doses of oxytocin used in these studies were near maximal ( $33 \mathrm{mU} / \mathrm{ml}$ ) and that identical results were obtained with supramaximal doses of oxytocin, suggest that DPH and oxytocin act at different sites or 'channels' of the external membrane of frog skin.

In order further to characterize the action of DPH, we investigated its interaction with 2 other drugs already known to be active on the external side of amphibian epithelia, i.e., amphotericin B, which increases sodium transport ${ }^{10}$ and amiloride, which decreases sodium transport ${ }^{11}$.

We found an interaction between DPH and amphotericin B. Statistical analyses of 12 'cross experiments' with these 2 drugs revealed that increments in SCC induced by DPH, with and without previous exposure to the polyene antibiotic, were significantly different $(p<0.001)$. Likewise, increments induced by amphotericin $B$, with and without previous exposure to the antiepileptic, were also significantly different $(p<0.001)$.

As far as amiloride is concerned, this diuretic, at a concentration of $10^{-4} M$, regularly blocked the effect of DPH, bringing $\mathrm{PD}$ and SCC down to zero or very near zero. The effect of amiloride was reversible and non-specific. The drug seemed to block all sodium 'channels' available at the outer surface of frog skin, not only those 'activated' by $\mathrm{DPH}$, but also those sensitive to amphotericin $\mathrm{B}$ and oxytocin. This was cleariy demonstrated in the experiment shown in Figure 3 , for both PD and SCC.

It should be emphasized that amphotericin B increased SCC but did not always decrease PD, as shown in Figure 3. Such variability has also been reported in toad bladder ${ }^{10}$.
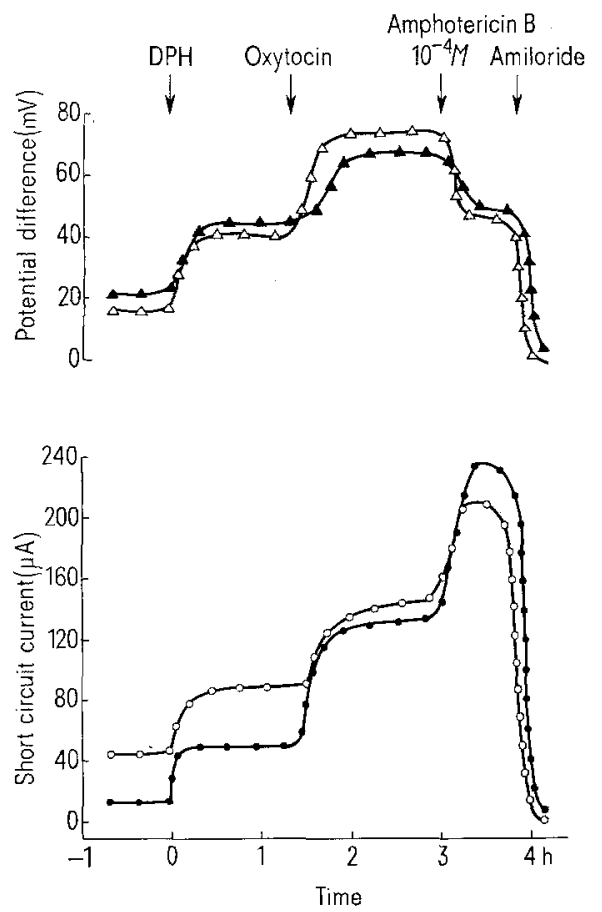

Fig. 3. Concomitant effects on $\mathrm{PD}$ and SCC of DPH, oxytocin, amphotericin B and amiloride, given successively to 2 areas of the same frog skin. Only oxytocin was added to the internal side. Set up: 'large' double chamber and clamp type 2 (see Methods).
Our results suggest that DPH and amphotericin B compete for similar 'sites' at the outer surface of frog skin while the mechanism of action of each drug seems quite distinct. Amphotericin B induces an increase in conductance accompanied by a loss of permselectivity, as if the drug produced micro-holes in the membrane ${ }^{12}$. On the other hand, DPH mimics the effects of oxytocin on PD and SCC with no apparent loss of permselectivity. DPH and oxytocin very likely have in common the capacity of changing the permeability to sodium at the outer surface of the skin, although they are added to opposite sides of the membrane.

Since submission of our eariier report ${ }^{6}$, effects of DPH on frog skin have also been reported by WATSON and WOODBURY ${ }^{13}$ and we have become aware of the work of Carroll and Pratley ${ }^{14}$. Despite their use of unusual bathing solutions, namely Ringer with a high $\mathrm{pH}^{13}$ and Ringer without calcium ${ }^{14}$, their results were similar to ours. Convincing evidence has been presented, showing that changes in sodium net flux quantitatively accounted for the changes in SCC induced by DPH ${ }^{13}$.

Work in progress suggests that mimicry of oxytocin by DPH is not mediated by cyclic AMP ${ }^{15}$, an observation of particular interest in relation to the investigation of the stimulus-effect coupling of neuropeptides in amphibian epithelia. One can speculate that the 'sites' activated by DPH bear some relation to the 'calcium sites' described by HERRERA and CURRAN ${ }^{16}$. This interpretation is strengthened by the finding that lanthanides, which strongly jnteract with calcium in many biological systems, produce effects similar to those of DPH on the external side of frog skin ${ }^{17-19}$.

Résumé. La diphénylhydantoïne agit sur la face externe de la peau de grenouille en provoquant une augmentation de la différence de potentiel et du courant de court circuit. L'effet est rapide, soutenu et réversible. Des interactions entre DPH, ocy tocine, amiloride et amphotéricine B ont été étudiées.

\section{R. C. de Sousa 20 and A. Grosso 21}

Département de Physiologie de l'Université,

Ecole de Médecine,

CH-1211 Genève 4 (Switzerland),

16 Avril 1973.

${ }^{10}$ I. Singer, M. M. Civan, R. F. Baddour and A. Leaf, Am. J. Physiol. 217, 938 (1969).

${ }^{11}$ E. N. Ehrlich and J. CrabBé, Pflügers Arch. ges. Physiol. 302, 79 (1968).

12 T. E. Andreoli, V. W. Dennis and A. M. Weigl, J. gen. Physiol. 53,133 (1969).

${ }^{13}$ E. L. Watson and D. M. Woodbury, J. Pharmac. exp. Ther. 180, 767 (1972).

${ }^{14}$ P. T. Carroll and J. N. Pratley, Comp. gen. Pharmac. 1, 365 (1970),

15 R. C. de Sousa and A. Grosso, Experientia 29, 748 (1973).

16 F. C. Herrera and P. F. Curran, J. gen. Physiol. 46, 999 (1963).

17 R. C. De Sousa, J. Marguerat and A. Grosso, Experientia 29, 749 (1973).

${ }^{18}$ We thank Sandoz Ltd and Merck Sharp \& Dohme for generous fifts of Syntocinon and Amiloride, respectively.

19 Supported by SNF grant No. 3.567.71.

20 Department of Medicine and Department of Physiology, University of Geneva (Switzerland).

${ }^{21}$ Department of Physiology, University of Geneva (Switzerland). 